\title{
Overview of fatigue Life Assessment of Baffles in Wendelstein 7-X
}

\author{
Joris Fellinger $^{\mathrm{a}^{*}}$, Roberto Citarellab ${ }^{\mathrm{b}}$, Venanzio Giannella ${ }^{\mathrm{b}}$, Marcello Lepore ${ }^{\mathrm{b}}$, Raffaele Sepe ${ }^{\mathrm{c}}$, \\ Michael Czerwinski ${ }^{\mathrm{a}}$, Friedemann Herold ${ }^{\mathrm{a}}$ and Reinhold Stadler ${ }^{\mathrm{d}}$ and the W7-X team \\ aMax-Planck-Institute of Plasma Physics, Wendelsteinstraße 1, 17491 Greifswald, Germany \\ bDepartment of Industrial Engineering, University of Salerno, Fisciano (SA), Italy \\ c Dept. of Chemical, Materials and Production Engineering, University of Naples Federico II, P.le V. Tecchi, 80, 80125 Naples, Italy \\ dMax-Planck-Institute of Plasma Physics, Boltzmannstraße 2, 85748 Garching, Germany \\ *Corresponding author: joris.fellinger@ipp.mpg.de
}

Wendelstein 7-X (W7-X), the world's largest nuclear fusion experiment of modular stellarator type, started operation in 2015 and will be upgraded with a water cooled first wall for steady state operation in 2020. The first wall consists of a CFC armored island divertors, adjacent baffles, heat shields, and stainless steel wall panels. Baffle and heat shield segments consist of graphite tiles, bolted with low pre-stress onto heat sinks of CuCrZr that are in turn brazed onto water cooled steel pipes.

Cracks were detected before installation in the baffles in the root of the brazed seam in over 100 locations. Such cracks are attributed to the imposed plastic deformation of the pipes to bring them into the final shape following the complex 3D geometry of the plasma vessel.

This paper gives an overview of the experimental and numerical work using finite element method (FEM) and dual boundary element method (DBEM), including sub-modelling to assess the risk of a water leak during operation. Details of the numerical work is published in $[3,4,5]$.

First fatigue crack growth experiments were carried out on pipe material and thermal-mechanical crack growth predictions were made with FEM and DBEM. It appeared that the Stress Intensity Factor (SIF) threshold of the ductile steel is only reached when large plastic strains occur, thus violating the field of application of linear elastic fracture mechanics to forecast crack growth.

Afterwards, representative brazed pipe samples were manufactured and subjected to initial plastic deformation causing cracks in 11 out of 12 samples. Some samples were tested up to 60000 bending load cycles. Two out of four samples failed after $\sim 35000$ cycles. Before and after the test, the shape of the cracks was measured using 3D computer tomography scans. Equivalence between thermal load in W7-X and the mechanical load in the cyclic test was determined with the numerical models to allow for a prediction of the fatigue life in W7X. Additional modeling showed that also plastic zones away from the cracks can limit the fatigue life.

Keywords: Wendelstein 7-X, first wall, fatigue, cracks, FEM, BEM, thermo-mechanics

\section{Introduction}

\subsection{Background}

The modular stellarator Wendelstein 7-X (W7-X) in Greifswald (Germany) successfully started operation in 2015 with short pulse limiter plasmas [1,2]. After an intermediate Operation Phase (OP1.2) in 2017-2018 in which island divertor plasmas are tested in short pulses, steady state operation (OP2) with the completed watercooled $1^{\text {st }}$ wall is planned to start in 2020.

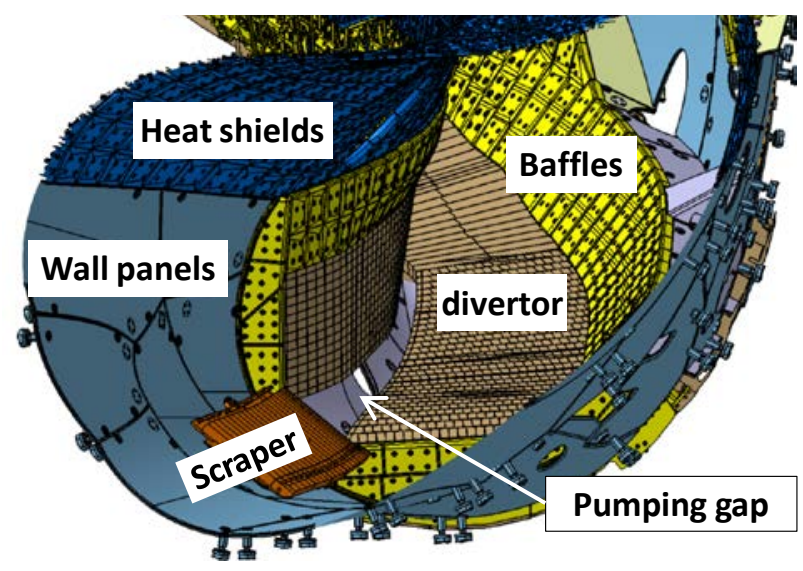

Figure 1: Overview of the 1st wall in W7-X

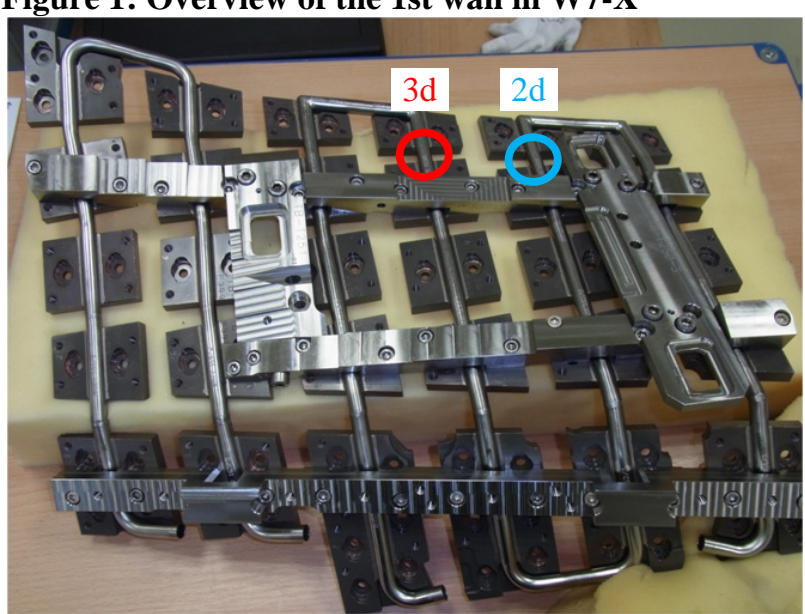

Figure 2: Baffle module $7 \mathrm{v}$ without graphite tiles and crack location $2 \mathrm{~d}$ and $3 \mathrm{~d}$, seen from the vessel side

The 1st wall is 10 fold symmetric and each module consists of an island divertor loaded with a convective heat flux up to $10 \mathrm{MW} / \mathrm{m}^{2}$, an adjacent baffle structure mainly loaded with radiative loads up to $500 \mathrm{~kW} / \mathrm{m}^{2}$, heat shields in areas with small distance to the last closed flux surface also designed against $500 \mathrm{~kW} / \mathrm{m}^{2}$ and 
stainless steel wall panels in the low loaded areas up to 200 kW/m², see Figure 1.

The baffles and heat shields are both made of graphite tiles that are with low but well-defined prestress bolted onto a heat sink of CuCrZr, see Figure 2. The heat sink is brazed onto a water-cooled steel pipe of $12 \mathrm{~mm}$ outer diameter and $1 \mathrm{~mm}$ thickness. The baffles are rigidly supported on a steel structure whereas the heat shields are flexibly connected with pins onto the plasma vessel wall. Although the baffles and heat shields are not yet water cooled in OP1.2, they are ready to be connected to the cooling for OP2.

\subsection{Crack problem}

The heat sinks of the baffles and heat shields were brazed onto the steel pipes with a $\mathrm{BNi}-2$ braze foil at $1050{ }^{\circ} \mathrm{C}$ and $10^{-4} \mathrm{mbar}$ and tempered at $475{ }^{\circ} \mathrm{C}$. Cut sections of the brazing shows good bond with very low porosity, see Figure 3.

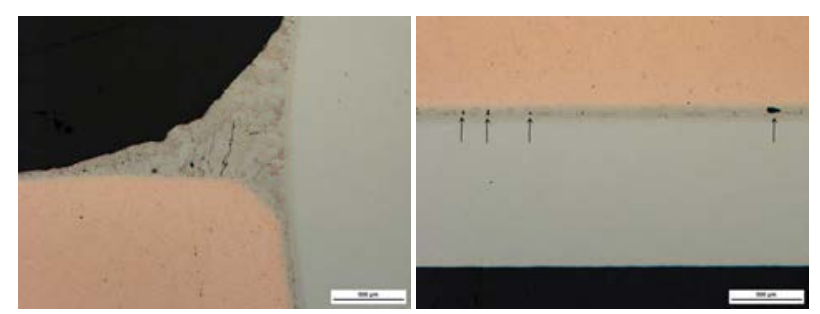

Figure 3: Typical cut sections after brazing with minor pores and minor internal cracks in the root

After brazing, the steel pipes were bent and twisted into their final shape on a bending machine in which the force was transferred from the machine via the heat sinks onto the pipes, see Figure 4. Hereafter, the steel pipe segments were welded together by orbital welding into complete baffle or heat shield modules.

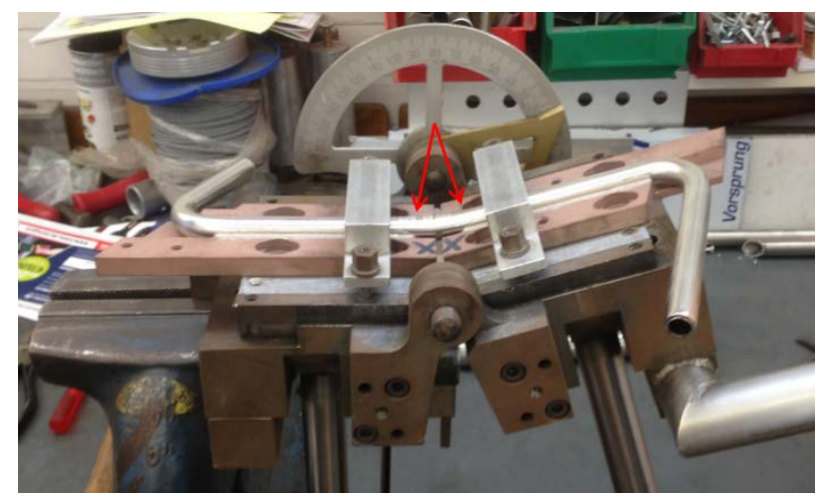

Figure 4: Bending machine to deform pipes into final shape.

After one brazed specimen was coincidentally severly cracked during bending, all baffles and heat shields were inspected for cracks in detail and it was found that 144 cracks had developed in the root of the braze in 31 different locations, see Figure 5. Note that each location exists 10 times due to stellarator symmetry. The fraction of cracked sections clearly increases for larger imposed deformation but there is also big scatter, see Figure 6.

None of the cracks directly caused a loss of leak tightness, but obviously it was feared that these initial cracks might jeopardize the fatigue life of the baffles and heat shields. Notably, some 1000 heating cycles per year are expected in OP2. Since the baffles are more rigidly supported that the heat shields, the steel pipes are subjected to higher restrained thermal forces during a heating cycle than the heat shields. Therefore, the assessment of the fatigue life concentrates on the baffles.
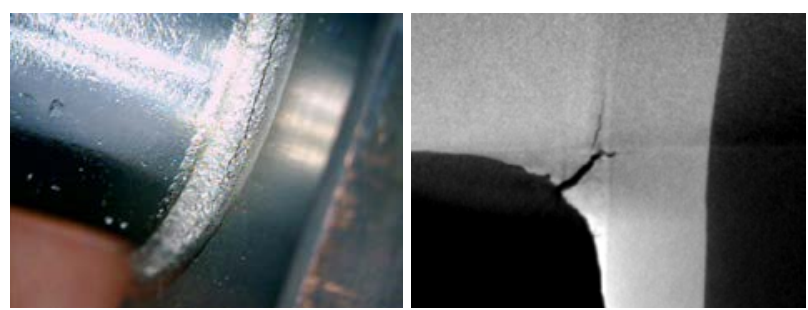

Figure 5: Photo of crack in root of braze (left) and CT scan (right)

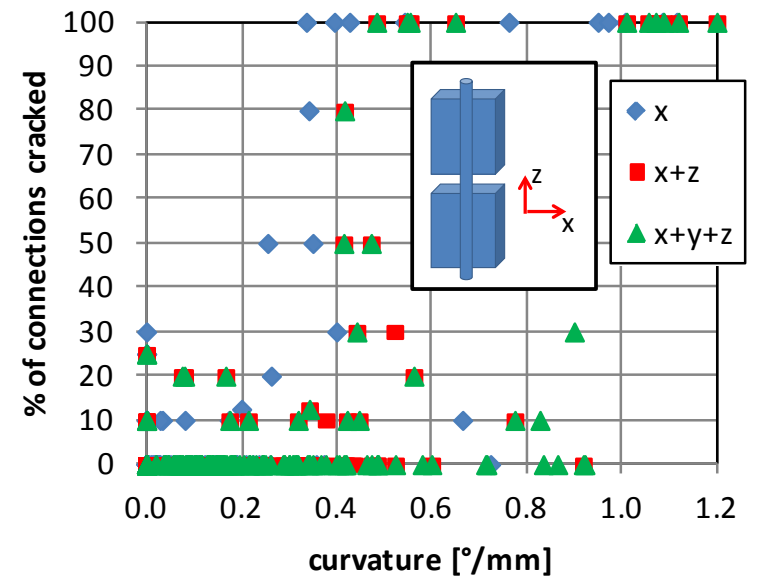

Figure 6: Fraction of cracked sections related to the amount of imposed deformation about 3 axes

\subsection{Approach}

To assess the fatigue life, first simple crack growth tests and simple tensile tests were carried out on pipe material. Also static and cyclic tests were carried out on baffle like samples of heat sinks brazed onto a steel pipe. All experiments and their corresponding computed tomography (CT) scans of the cracks are described in the next section. The experimental work was supported by analysis using finite element method (FEM) and dual boundary element method (DBEM) [3, 4,53]. This is described in section 3 . The consequences for the fatigue life of the baffles and operation of the machine are discussed in section 4 .

\section{Experiments}

In support of numerical analysis, experiments were carried out at the University of Salerno, Italy.

To verify the impact of the manufacturing process of the pipes on the mechanical properties, five simple tensile tests on pieces of stainless steel pipe EN 1.4441 were carried out, three on an MTS electromechanical machine using extensometers to measure the strains and two more tests on an Instron 8500 hydraulic machine using strain gauges to measure the strains. The results are summarized in Table 1. 
Next, two fatigue crack growth rate tests according to ASTM 647 were conducted on compact tension samples of stainless steel EN 1.4441 of $60 \times 63 \times 5 \mathrm{~mm}$ with a $40^{\circ}$ $\mathrm{V}$-shaped notch made by electrical discharge machining. The fatigue crack growth was measured with four crack gauges (2 at each side). The resulting Paris' law for crack growth rate with crack size $a$ in $\mathrm{mm}$ and stress concentration factor $\Delta K$ in the range of $400<\Delta K<700 \mathrm{MPa} \sqrt{\mathrm{mm}}$ was

$$
\frac{d a}{d N}=1.68 \cdot 10^{-14} \Delta K^{3.18}
$$

causing a growth of 3-18 $\mu \mathrm{m} / 1000$ cycles in this range.

Table 1: Summary of static tensile test results

\begin{tabular}{|c|c|c|c|c|}
\hline $\begin{array}{c}\text { Sample } \\
\text { ID }\end{array}$ & $\begin{array}{c}\text { Young's } \\
\text { modulus } \\
\text { [GPa] }\end{array}$ & $\begin{array}{c}\text { Yield } \\
\text { limit } \\
\text { [MPa] }\end{array}$ & $\begin{array}{c}\text { Tensile } \\
\text { strength } \\
\text { [MPa] }\end{array}$ & $\begin{array}{c}\text { Ultimate } \\
\text { strain } \\
\text { [\%] }\end{array}$ \\
\hline 1 & 153 & 225 & 511 & 40 \\
2 & 151 & 227 & 511 & 41 \\
3 & 155 & 226 & 510 & 40 \\
4 & 151 & 222 & 507 & 41 \\
5 & 149 & 223 & 509 & 40 \\
\hline Mean & 152 & 225 & 510 & 40.4 \\
St.dev. & 2.2 & 2.1 & 1.7 & 0.5 \\
\hline
\end{tabular}

Finally, two static and four cyclic bending tests were carried out at room temperature. For that purpose, six baffle-like specimens were manufactured. For each specimen three heat sinks were brazed onto a stainless steel pipe, see Figure 7. After brazing, both steel sections between the heat sinks were bent and twisted according to the same procedure as for the real baffles, causing 20 out of 24 braze roots to crack. Some of the cracks propagated into the steel pipe. Before testing, 3D CT scans were made for 15 of 20 cracked roots, and for those that were cyclically tested, a $2^{\text {nd }} \mathrm{CT}$ scan was made afterwards. CT scans from tested roots were also transformed into CAD geometry, see Figure 8.

During the static and cyclic tests, the pressure in the pipe was monitored to detect a leak, see Figure 7. A load ratio between maximum and minimum load of $\mathrm{R}=0.1$ was applied during the cyclic tests.

In the cyclic test on P6-2-3 that failed after 30k cycles, the leak detection was lost and actual leak must have taken place much earlier.

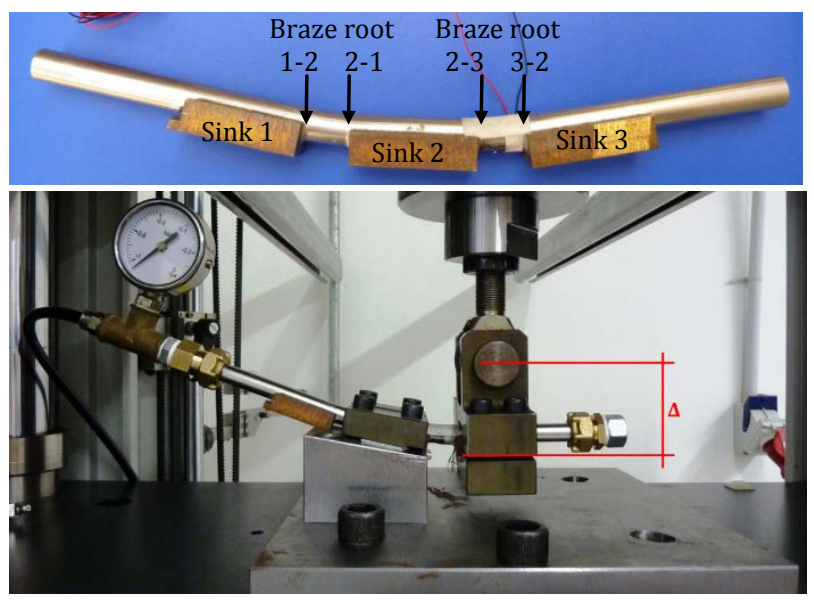

Figure 7: baffle like specimen after initial bending (top) and test set up (bottom)
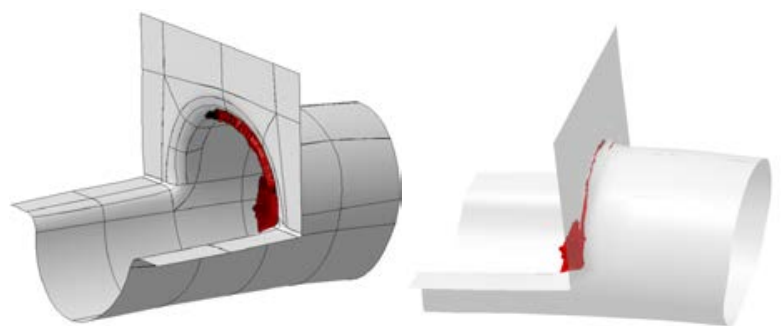

Figure 8: $1^{\text {st }}$ CAD geometry from CT scan P6-2-3

Table 2: Overview of the tests on baffle like samples

\begin{tabular}{|c|c|c|c|c|c|c|c|c|}
\hline Sample & root & $\begin{array}{c}\text { Bend } \\
\text { ing } \\
{[\% / m} \\
m]\end{array}$ & $\begin{array}{l}\text { Torsion } \\
{[\% / \mathrm{mm}]}\end{array}$ & \begin{tabular}{|l|} 
Initial \\
Crack*
\end{tabular} & $\begin{array}{l}\text { Load } \\
{[\mathrm{kN}]}\end{array}$ & $\begin{array}{l}\text { Cycles } \\
\text { [x10³ }\end{array}$ & $\begin{array}{l}\text { CT } \\
\text { scan }\end{array}$ & $\begin{array}{l}\text { CAD } \\
\text { file }\end{array}$ \\
\hline \multirow[b]{2}{*}{ P1 } & $\begin{array}{l}1-2 \\
2-1\end{array}$ & 0.6 & 0 & no & \multirow{2}{*}{$\begin{array}{c}1.0 \\
- \\
- \\
1.0\end{array}$} & \multirow{2}{*}{$\begin{array}{c}\text { tbd } \\
- \\
- \\
60 \mathrm{nf}\end{array}$} & \multirow{2}{*}{$\begin{array}{c}\text { tbd } \\
- \\
- \\
y\end{array}$} & \multirow[t]{2}{*}{ tbd } \\
\hline & $\begin{array}{l}2-1 \\
2-3 \\
3-2\end{array}$ & 1.0 & 0 & $\begin{array}{l}\text { small } \\
\text { many }\end{array}$ & & & & \\
\hline \multirow{2}{*}{ P2 } & $\begin{array}{l}1-2 \\
2-1\end{array}$ & 0.8 & 0 & $\begin{array}{l}\text { yes } \\
\text { yes }\end{array}$ & \multirow{2}{*}{$\begin{array}{c}- \\
0.5 \\
- \\
0.5\end{array}$} & \multirow[t]{2}{*}{-} & \multirow[t]{2}{*}{$1 \mathrm{x}$} & \multirow{2}{*}{$\begin{array}{l}- \\
- \\
- \\
-\end{array}$} \\
\hline & $\begin{array}{l}2-3 \\
3-2\end{array}$ & 1.1 & 0 & $\begin{array}{l}\text { yes } \\
\text { yes }\end{array}$ & & & & \\
\hline \multirow{2}{*}{ P3 } & $\begin{array}{l}1-2 \\
2-1\end{array}$ & 0.7 & 0 & $\begin{array}{l}\text { pipe } \\
\text { small }\end{array}$ & \multirow{2}{*}{$\begin{array}{c}- \\
1.0 \\
- \\
-\end{array}$} & \multirow{2}{*}{$\begin{array}{c}- \\
34 \\
- \\
-\end{array}$} & $\begin{array}{l}- \\
2 x\end{array}$ & \multirow{2}{*}{$\begin{array}{c}- \\
2 \mathrm{x} \\
- \\
-\end{array}$} \\
\hline & $\begin{array}{l}2-3 \\
3-2\end{array}$ & 0.6 & 0 & $\begin{array}{c}\text { no } \\
\text { yes }\end{array}$ & & & $\begin{array}{c}- \\
1 \mathrm{x}\end{array}$ & \\
\hline \multirow{2}{*}{ P4 } & $\begin{array}{l}1-2 \\
2-1\end{array}$ & 0.6 & 0.53 & $\begin{array}{c}\text { no } \\
\text { yes }\end{array}$ & \multirow{2}{*}{$\begin{array}{c}- \\
- \\
0.5 \\
1.0\end{array}$} & \multirow{2}{*}{$\begin{array}{c}- \\
- \\
\text { tbd } \\
60 \mathrm{nf}\end{array}$} & $\begin{array}{c}- \\
1 \mathrm{x}\end{array}$ & \multirow{2}{*}{$\begin{array}{c}- \\
- \\
\text { tbd } \\
2 \mathrm{x}\end{array}$} \\
\hline & $\begin{array}{l}2-3 \\
3-2\end{array}$ & 0.7 & 0.41 & $\begin{array}{l}\text { pipe } \\
\text { pipe }\end{array}$ & & & $\begin{array}{l}\text { tbd } \\
2 x\end{array}$ & \\
\hline \multirow{2}{*}{ P5 } & $\begin{array}{l}1-2 \\
2-1\end{array}$ & 0.7 & 0.24 & $\begin{array}{l}\text { small } \\
\text { pipe }\end{array}$ & \multirow{2}{*}{$\begin{array}{c}- \\
4.7 \\
- \\
\text { tbd }\end{array}$} & \multirow{2}{*}{$\begin{array}{c}- \\
\text { static } \\
- \\
\text { static }\end{array}$} & $\begin{array}{l}1 \mathrm{x} \\
1 \mathrm{x}\end{array}$ & \multirow{2}{*}{$\begin{array}{l}- \\
- \\
- \\
-\end{array}$} \\
\hline & $\begin{array}{l}2-3 \\
3-2\end{array}$ & 0.6 & 0.29 & $\begin{array}{l}\text { yes } \\
\text { yes }\end{array}$ & & & $\begin{array}{l}1 \mathrm{x} \\
1 \mathrm{x}\end{array}$ & \\
\hline \multirow{2}{*}{ P6 } & $\begin{array}{l}1-2 \\
2-1\end{array}$ & 0.9 & 0.24 & $\begin{array}{c}\text { small } \\
\text { yes }\end{array}$ & & \multirow{2}{*}{$\begin{array}{c}- \\
- \\
30 \\
-\end{array}$} & \multirow[b]{2}{*}{$\begin{array}{l}2 x \\
1 x\end{array}$} & \multirow{2}{*}{$\begin{array}{c}- \\
- \\
2 \mathrm{x} \\
-\end{array}$} \\
\hline & $\begin{array}{l}2-3 \\
3-2\end{array}$ & 0.9 & 0.24 & $\begin{array}{l}\text { pipe } \\
\text { pipe }\end{array}$ & & & & \\
\hline
\end{tabular}

* pipe $=$ the crack extended into the steel pipe, tbd = to be done, $\mathrm{nf}=$ no failure.

\section{Numerical analyses}

\subsection{Assessment of stress state under heat loads}

First, a global FE model of the baffle module $7 \mathrm{v}$ (see Figure 2) was created with linear thermal elements and quadratic mechanical elements and sequential thermalmechanical calculations were performed for uniform heat loads at the plasma facing side ranging from 100$250 \mathrm{~kW} / \mathrm{m}^{2}$. The mechanical calculation is first loaded by water pressure of 25 bar in the cooling pipes and then the transient temperature distribution obtained from the thermal model.

The baffle module is rigidly supported on the plasma vessel wall. Bolted connections between the stainless steel support structure and the heat sinks are assumed to be tied. As the graphite tiles can slide onto the heat sinks, they have been ignored in the mechanical model. The thermal conductance between graphite and heat sink was calibrated at $3 \mathrm{~kW} / \mathrm{m}^{2} \mathrm{~K}$ using temperature readings in a former thermal test on a single baffle tile [6]. The thermal conductance between water and cooling pipe 
was derived from [7, s. 383] at $15 \mathrm{~kW} / \mathrm{m}^{2} \mathrm{~K}$ based on a water speed of $3 \mathrm{~m} / \mathrm{s}$. Further details on mesh and material properties are given in [3].

Then, a default sub-model of the brazed connection modeled continuously was extracted from the global model with cuts through the steel pipe and heat sink. The braze geometry and mesh were refined and sub-models for FEM as well as DBEM were generated. The default sub-model could then be repositioned at any location of interest as found in the global model to impose the transient temperatures and displacements as calculated with the global model at the cut sections of the thermal and mechanical sub-models respectively. In addition, the transient temperature field over the entire sub-model as calculated with the thermal sub-model was transferred as input to the mechanical sub-model.

A simplified crack of similar size as found with the CT scan was modeled in the sub-model located at braze root $3 \mathrm{~d}$ of baffle $7 \mathrm{v}$. The analyses show that yielding at the root of the braze remains limited to small scale up to a heat load of $\sim 100 \mathrm{~kW} / \mathrm{m}^{2}$. At $150 \mathrm{~kW} / \mathrm{m}^{2}$, significant yielding occurs, see Figure 9. Linear elastic fracture mechanics is not applicable in this case because the plastic radius at the crack tip is too large relative to the crack size and pipe thickness. At lower loads up to 100 $\mathrm{kW} / \mathrm{m}^{2}, \Delta K$ remains limited to $\sim 150 \mathrm{MPa} \sqrt{\mathrm{mm}}$, see Figure 10, which is clearly below the threshold value for crack growth (compare with the crack propagation test at 400-700 MPa $\sqrt{\mathrm{mm}}$ ). So the crack gives a minor contribution to the overall failure (at least initially) and plastic behavior dominates. It means that fatigue life will be dominated by low cycle fatigue based on yielding (obviously fatigue will be accelerated by crack propagation). Therefore, in section 3.3 the low cycle fatigue based on plastic strain cycles is assessed.

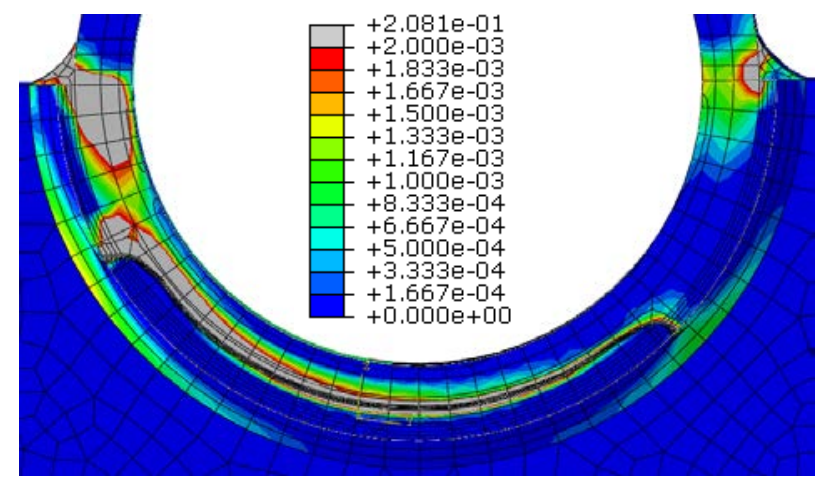

Figure 9: Plastic strain magnitude at crack tip 3d on baffle model $7 \mathrm{v}$ exposed to $150 \mathrm{~kW} / \mathrm{m}^{2}$

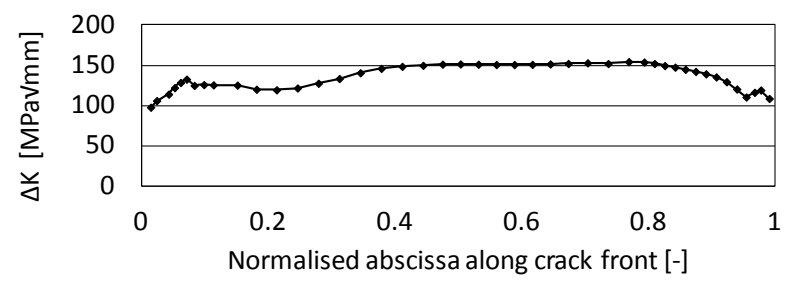

Figure 10: $\Delta K$ along crack tip 3d on baffle module 7v exposed to $100 \mathrm{~kW} / \mathrm{m}^{2}$
3.2 Equivalence of cyclic tests with thermal loads in W7-X

In order to be able to interpret the cycles to failure in the mechanically loaded cyclic tests of section 2 with thermally loaded baffles in W7-X, $\Delta K$ (up to $\sim 100$ $\mathrm{kW} / \mathrm{m}^{2}$ ) and plastic strain magnitude (for loads $>\sim 150$ $\mathrm{kW} / \mathrm{m}^{2}$ ) were compared between baffle $7 \mathrm{v}$ and the cyclic test set up.

First, the static test was used to calibrate the stiffness of the testing machine represented by a spring in the FE model. For the cyclic test, the CAD geometry of initial crack of sample P3-2-1 was modeled. In a first step, the initial curvature of $0.7^{\circ} / \mathrm{mm}$ of cyclic test sample P3-2-1 was applied while the crack is forced to remain closed. In a $2^{\text {nd }}$ step, the initial deformation is released and the crack is allowed to open. Residual stresses remain leading to fairly constant negative $K_{I}$ values along the crack tip of about $-25 \mathrm{MPa} \sqrt{\mathrm{mm}}$. In a $3^{\text {rd }}$ step, the mechanical load is applied. Similar values of $K_{I}$ along the crack tip are obtained for a heat load on baffle module $7 \mathrm{v}$ at $2 \mathrm{~d}$ of $100 \mathrm{~kW} / \mathrm{m}^{2}$ and a mechanical load in the test of $500 \mathrm{~N}$. For higher loads, the plastic strain magnitude at the crack tip was used to compare the mechanical test with heat loads in W7-X since linear elastic fracture mechanics is no longer applicable. As shown in Figure 11, $1 \mathrm{kN}$ of the test corresponds with $\sim 220 \mathrm{~kW} / \mathrm{m}^{2}$ for baffle module $7 \mathrm{v}$ at crack location 3d.

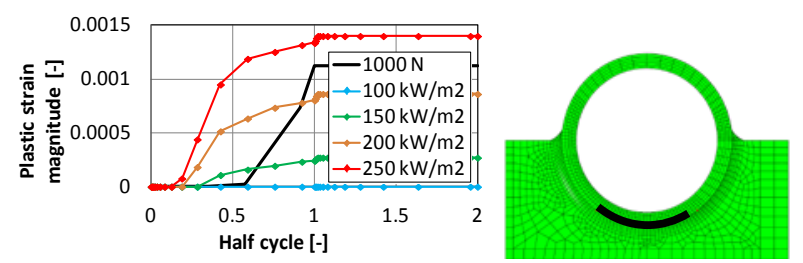

Figure 11: Comparison of plastic strain magnitude averaged along crack (black line) between heat loads on baffle 7v (location 3d) and cyclic test load of 1 kN

\subsection{Low cycle fatigue assessment without cracks}

Global FE models were prepared for all 17 baffle module types. The equivalent plastic strain after one heating cycle was extracted for all 31 locations where cracks were found. A local sub-model was made for 10 of these locations (characterized by either high plastic strain or 10/10 baffles cracked) to assess the low cycle fatigue life based on consecutive heating and cooling cycles. Three transient heating and cooling cycles up to thermal equilibrium were simulated, for both global and local models, showing acceptable stabilization after the $2^{\text {nd }}$ cycle. Yielding of the steel pipe due to bending during manufacturing was not taken into account since it would complicate modeling considerably and it is a onetime yielding only can only marginally affect the stabilized plastic stress-strain cycle. The stress-strain results of the $3^{\text {rd }}$ cycle of the sub-models were then transferred to the fatigue assessment software FE-safe [11].

The stainless steel was modeled using a nonlinear kinematic hardening model (Chaboche-type) with von 
Mises yield criterion [9,10]. Hardening model parameters were fitted to the hysteresis loop based on the cyclic stress-strain curves for 316L of [8]. Fatigue life was determined by the plastic strain amplitude $\Delta \varepsilon / 2$ and optionally by mean stress $\sigma_{m}$ (Morrow correction) using a Coffin-Manson relation, i.e.

$$
\frac{\Delta \varepsilon}{2}=\frac{\sigma_{f}-\sigma_{m}}{E}\left(2 N_{f}\right)^{b}+\varepsilon_{f}\left(2 N_{f}\right)^{c}
$$

With $\sigma_{f}=560 \mathrm{MPa}, \varepsilon_{f}=0.08, b=-0.08, c=-0.53$ fitted to the fatigue curve for 316L of [8].

Three multi-axial low cycle fatigue criteria were used that consider the plastic strain parameter $(\Delta \varepsilon / 2)$ in the Coffin-Manson law differently: the normal strain amplitude, the shear strain amplitude or the mean of both. Amplitudes are evaluated node by node on planes with different orientation to find the most critical plane on which the estimated fatigue life is the lowest. Results for baffle module $7 \mathrm{v}$ at $3 \mathrm{~d}$ are shown in Figure 12. The Young's modulus $E=158 \mathrm{GPa}$ was taken from the tensile tests, see Table 1 . It was confirmed that the effect on fatigue life using a common literature value of 200 GPa was negligible: For location 3d of baffle module $7 \mathrm{v}$ a change of E from 158 to $200 \mathrm{GPa}$ resulted in a change of the equivalent plastic strain after one cycle from 2.92 to $2.97 \%$ only.

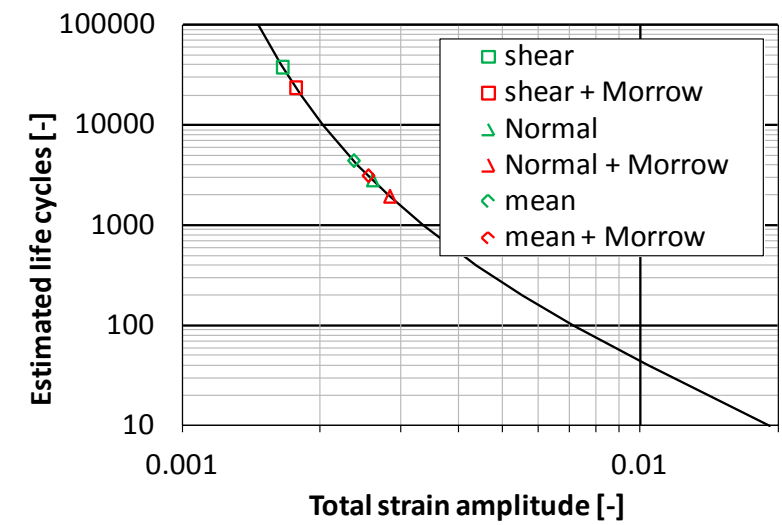

Figure 12: Fatigue life for location $3 d$ in baffle module $7 v$

\section{Discussion}

For the 10 considered locations, the low cycle fatigue life ranges from as low 30 cycles up to 25k cycles was found. Notably, the Coffin-Manson curve has a typical safety factor of 20 for the number of cycles or 2 for the strain amplitude. Moreover, fatigue describes the number of cycles up to the nucleation of a crack. As determined in section 2, propagation of the crack up to a water leak can still take $30 \mathrm{k}$ cycles or more.

Nevertheless, the baffles are a critical component. The most uncertain parameter is the heat load. Better understanding of the heat loads will be gained in OP1.2. During OP1.2, thermal stress is less critical as the baffles are not yet cooled and thermal equilibrium is not reached in short pulses.
Thermal stress is driven by the incompatible thermal deformation between the steel pipe and the heat sink: The stainless steel pipe tends to bend due to a large thermal gradient as only one half is heated, while the heat sink remains flat as the CuCrZr conducts heat very well which results in a far more uniform temperature. Moreover, the rigid steel support structure of the baffles is connected to the heat sinks without further cooling, and it heats up more than the cooling pipes and adds significant additional thermal stress.

In case design heat loads of the baffles are confirmed in OP1.2, counter measures are required. One improvement could be to allow some flexibility between the rigid steel support and the heat sinks. Alternatively, a copper shield between the support structure and the baffles covering the steel pipes could reduce the thermal gradient in the cooling pipe.

\section{Acknowledgments}

This work has been carried out within the framework of the EUROfusion Consortium and has received funding from the Euratom research and training programme 2014-2018 under grant agreement No 633053. The views and opinions expressed herein do not necessarily reflect those of the European Commission.

\section{References}

[1] Bosch, H.S. et al.: Experience with the commissioning of the superconducting stellarator Wendelstein 7-X, Fusion Engineering Design 96-97, 2015, pp 22-25

[2] Wolf, R. et al.: Major results from the first plasma campaign of the Wendelstein 7-X stellarator, Nuclear Fusion 57.10, 2017

[3] Giannella, V. et al.: Multiaxial LCF assessment on Plasma Facing Components of fusion experiment "Wendelstein 7X, AIMETA Conference 2017, Salerno, Italy www.aimeta2017.unisa.it/node/53, pp 1047-1061

[4] Lepore, M. et al.: Crack modeling in baffle modules of nuclear fusion experiment "Wendelstein 7-X", AIMETA Conference 2017, Salerno, Italy www.aimeta2017.unisa.it/node/53, pp 1006-1017

[5] Citarella, R. et al.: FEM-DBEM approach to analyse crack scenarios in a baffle cooling pipe undergoing heat flux from the plasma, Materials Science and Engineering 274 (to be published)

[6] Greuner et al.: Final design of W7-X divertor plasma facing components tests and thermo-mechanical analysis of baffle prototypes, Fusion Engineering and Design 66-68 (2003) 447-452

[7] Polifke W. \& Kopitz, J.: Wärmeübertragung, Pearson 2005

[8] RCC-MR (2007)

[9] Abaqus Documentation, Version 6.14.1 (2014).

[10] Lemaitre, J., and J.-L. Chaboche, Mechanics of Solid Materials, Cambridge University Press, 1990.

[11] Fe-safe User Guide (2016) 